
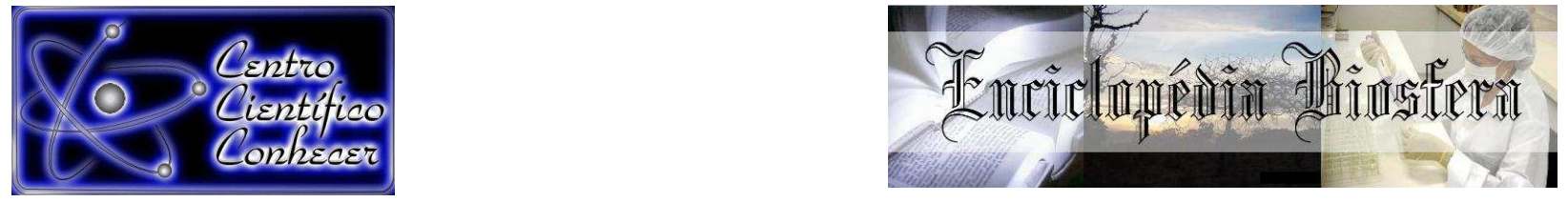

\title{
AVALIAÇÃO DA CAPACIDADE DE DEGRADAÇÃO DE HIDROCARBONETOS E FENOL POR ISOLADOS BACTERIANOS ENDOFÍTICOS DE BAMBU
}

Igor Daniel Alves Ribeiro ${ }^{1}$, Bruno Francesco Rodrigues de Oliveira ${ }^{2}$, Ariana Alves

Rodrigues $^{3}$, Sérgio Tadeu Sibov ${ }^{4}$, José Daniel Gonçalves Vieira ${ }^{5}$

1 Graduando do curso de Biotecnologia, Universidade Federal de Goiás

2 Professor Mestre do Departamento de Bioquímica e Biologia Molecular do Instituto de Ciências Biológicas da Universidade Federal de Goiás

(bfro.francesco@gmail.com)

3 Doutoranda em Ciências Ambientais, Universidade Federal de Goiás

4 Professor Doutor do Departamento de Genética do Instituto de Ciências Biológicas da Universidade Federal de Goiás

5 Professor Doutor do Departamento de Microbiologia, Imunologia, Parasitologia e Patologia do Instituto de Patologia Tropical e Saúde Pública da Universidade Federal de Goiás Goiânia-Brasil

Recebido em: 08/04/2016 - Aprovado em: 30/05/2016 - Publicado em: 20/06/2016 DOI: 10.18677/Enciclopedia_Biosfera_2016_123

\begin{abstract}
Bactérias endofíticas exibem uma ampla potencialidade biotecnológica, não se limitando a promoção do crescimento vegetal, sendo frequentemente também descritas por sua capacidade biorremediadora. Esses micro-organismos participam desde a degradação de hidrocarbonetos e demais poluentes orgânicos até a remediação de metais pesados, elevando significativamente a eficiência de sistemas fitorremediadores. O objetivo deste estudo foi avaliar qualitativamente a capacidade de degradação de hidrocarbonetos e a tolerância ao fenol por bactérias endofíticas de Bambu. Para a triagem da degradação de hidrocarbonetos, foram realizados testes em microplacas com cultivo microbiano utilizando cada um dos seguintes compostos como fonte única de carbono: óleo Diesel, gasolina, querosene, óleo queimado e óleos lubrificantes (20W40, 20W50, 5W50 e 15W40). Para a análise da tolerância ao fenol, os endofíticos foram cultivados em meio mínimo mineral sólido, utilizando fenol como fonte única de carbono em três concentrações: 50, 100 e 150 $\mathrm{mg} / \mathrm{L}$. Para os 21 isolados bacterianos avaliados, um isolado (7F) apresentou capacidade de degradação total dos combustíveis (óleo diesel, gasolina e querosene), e dois isolados (9F e 6F) exibiram capacidade de degradação parcial. A degradação de óleo vegetal foi observada para três isolados (6F, 7F e 9F) e parcialmente para o isolado 10F. A degradação dos óleos lubrificantes totais testados foi observada parcialmente por um isolado $(7 \mathrm{~F})$, sendo a degradação dos óleos $5 \mathrm{~W} 50$ e 15W40 parcial para o isolado 8F. Quinze isolados foram tolerantes ao fenol em todas as concentrações analisadas. Os resultados sugerem uma potencial aplicação dos isolados bacterianos endofíticos selecionados em processos de biorremediação.
\end{abstract}

RESUMO

PALAVRAS-CHAVE: Fenol, hidrocarbonetos, micro-organismos endofíticos 


\title{
SCREENING OF HYDROCARBON DEGRADATION CAPACITY AND PHENOL TOLERANCE BY BACTERIAL ENDOPHYTIC ISOLATES FROM BAMBOO
}

\begin{abstract}
Endophytic bacteria exhibit a wide biotechnological potential, not limited to the plant growth promotion, and often also described by their bioremediation capacity. These microorganisms participate from the hydrocarbon degradation and other organic pollutants, to heavy metals remediation, elevating significantly the efficiency of phitoremediation systems. The aim of this study was to evaluate qualitatively the hydrocarbon degradation capacity and phenol tolerance by endophytic bacteria from bamboo. For the hydrocarbon degradation screening, it was performed tests in microplates with the microbial cultivation using each one of the following compounds as a sole carbon source: diesel oil, gasoline, kerosene, burned oil, lubricants (20W40, 20W50, 5W50 and 15W40). For phenol tolerance analysis, the endophytic were cultivated in mineral minimum solid medium, using phenol as the sole carbon source in three concentrations: 50, 100 and $150 \mathrm{mg} / \mathrm{L}$. For the 21 evaluated bacterial isolates, one isolate (7F) presented the fuel degradation capacity (diesel oil, gasoline and kerosene), and two isolates (9F and 6F) exhibited partial degradation capacity. The vegetal oil degradation was observed for three isolates (6F, 7F and $9 \mathrm{~F}$ ) and partially for the isolate 10F. The degradation for the tested lubricants was observed partially for one isolate (7F), with the partial degradation for $5 \mathrm{~W} 50$ and $15 \mathrm{~W} 40$ oils by the $8 \mathrm{~F}$ isolate. Fifteen isolates were tolerant to phenol in all the analyzed concentrations. The results suggest a potential application of the endophytic bacterial isolates in bioremediation process.
\end{abstract}

KEYWORDS: endophytic microorganisms, hydrocarbons, phenol.

\section{INTRODUÇÃO}

Petróleo e seus produtos derivados, os quais constituem a principal fonte energética do planeta e possuem papéis essenciais na vida moderna, consistem em misturas químicas complexas de componentes não-aquosos e hidrofóbicos, como alcanos, substâncias aromáticas, resinas e asfaltenos. O volume de óleo bruto e derivado de petróleo empregado atualmente é significativamente maior do que outros produtos químicos e a contaminação ambiental por esses compostos é uma preocupação global devido a toxicidade e persistência em quaisquer locais eventualmente contaminados (DAS \& CHANDRAN, 2011; LIU et al., 2011; ITE et al., 2013; PINEDO et al., 2013). Com o uso exponencial desses combustíveis fósseis desde o século XVIII até os dias atuais, acidentes levando ao derramamento e exposição no ambiente desses derivados tornaram-se comuns, não afetando apenas o equilíbrio dos ecossistemas afetados, contudo também a saúde humana, sendo já conhecidos efeitos deletérios de subprodutos desses componentes, como parafenóis e benzeno volátil, a nível hematológico, renal, respiratório e até neurológico (D'ANDREA \& REDDY, 2014).

Para a limpeza de áreas sujeitas à exposição por hidrocarbonetos do petróleo, vários métodos físico-químicos e de biorremediação foram delineados e vem sendo empregados. Dentre as técnicas de biorremediação, tem-se a fitorremediação, a aplicação de plantas para a remoção de poluentes do ambiente ou, no mínimo, torná-los em produtos menos danosos ao ambiente. Esse processo pode ser dividido em vários outros, no entanto, o que tem se destacado nos últimos anos é na convergência com a biorremediação microbiana, uma vez que os micro- 
organismos possuem evoluídos mecanismos de ativar enzimaticamente hidrocarbonetos, gerando intermediários que podem ser canalizados para as vias metabólicas centrais (GERHARDT et al., 2009; FUENTES et al., 2014; LAGHLIMI et al., 2015). A associação simbiótica entre os micro-organismos endofíticos da própria planta tem sido aproveitada em fitorremediação, com uma notável vantagem de evitar efeitos fitotóxicos de contaminantes como metais pesados, hidrocarbonetos policíclicos aromáticos (HPAs) e halogenados, que geralmente podem surgir durante o processo quando conduzido de modo isolado (LI et al., 2012).

Bactérias e fungos endofíticos são aqueles que colonizam tecidos e órgãos dos vegetais internamente sem prejudicar ou induzir sintomas de doença nos hospedeiros. Esses micro-organismos geralmente interagem com as plantas, produzindo fatores de crescimento vegetal, enzimas extracelulares, sideróforos, pigmentos, compostos detoxificantes e antimicrobianos, além de vias e produtos metabólicos fisiologicamente importantes compartilhados com 0 vegetal, promovendo o estabelecimento de uma relação benéfica e majoritariamente vantajosa ao hospedeiro (REINHOLD-HUREK \& HUREK, 2011; DUDEJA et al., 2012). A enorme variedade de vias metabólicas empregadas por endofíticos potencializa a aplicação em biorremediação, como por exemplo para a assimilação de metano, fixação de nitrogênio, degradação de pesticidas e hidrocarbonetos, além da biotransformação de xenobióticos e derivados tóxicos orgânicos (STEPNIEWSKA \& KUZNIAR, 2013).

Embora as plantas possam metabolizar ou sequestrar poluentes orgânicos, elas não dependem exclusivamente desses compostos como fontes de carbono e energia. Portanto, os vegetais necessitam dos endofíticos associados, principalmente bactérias, para degradação desses agentes ambientalmente danosos (AFZAL et al., 2014). No caso de fitorremediação de poluentes de natureza orgânica, endofíticos com os genes da via de degradação dessas substâncias podem diminuir a fitotoxicidade e evapotranspiração, além da capacidade de produzir sideróforos, ácidos orgânicos, biossurfactantes ou substâncias poliméricas extracelulares ou glicoproteínas que possibilitam a mobilização, captura e aumento da tolerância aos metais pesados pelo vegetal. Recentemente, foi observado que a aplicação de bactérias endofíticas com ambas as atividades de metabolização de poluentes hidrofóbicos e geração de fatores de crescimento vegetal é superior no âmbito da fitorremediação, ao invés de organismos que exibem apenas uma dessas atividades (WEYNES et al., 2010; RAJKUMAR et al., 2012; KHAN et al., 2013).

Devido a facilidade de manutenção e manipulação dos micro-organismos e a capacidade de aumentar a tolerância da planta a um determinando agente poluente, um grande interesse tem sido despertado na seleção, avaliação e melhoramento genético de endofíticos para otimização do processo de fitorremediação de modo global (DOTY, 2008; IJAZ et al., 2015). Sob essa perspectiva, o objetivo deste estudo foi avaliar qualitativamente a capacidade de degradação de hidrocarbonetos e a tolerância ao fenol por bactérias endofíticas de bambu.

\section{Micro-organismos e condições de cultivo}

\section{MATERIAL E MÉTODOS}

Foram utilizadas 21 bactérias endofíticas pertencentes a coleção de microorganismos do Laboratório de microbiologia ambiental e biotecnologia (LAMAB), da Universidade Federal de Goiás- UFG. Os isolados bacterianos foram previamente obtidos a partir das espécies de Bambu: Dendrocalamus asper (Schultes f.) Backer 
ex Heyne e Bambusa oldhamii Munro. Os micro-organismos foram cultivados em caldo TSB (Caldo Triptona de Soja) a $30{ }^{\circ} \mathrm{C}$ por 24 horas para realização dos ensaios de triagem da degradação de hidrocarbonetos e tolerância ao fenol.

\section{Triagem da degradação de hidrocarbonetos}

Para o ensaio de triagem da degradação de hidrocarbonetos, os isolados crescidos previamente foram inoculados em meio Mínimo ( $\mathrm{NaCl} 0,5 \% ; \mathrm{K}_{2} \mathrm{HPO}_{4}$ 0,1\%; $\mathrm{NH}_{4} \mathrm{HPO}_{4}$ 0,1\%; $\left(\mathrm{NH}_{4}\right)_{2} \mathrm{SO}_{4}$ 0,1\%; $\mathrm{MgSO}_{4} .7 \mathrm{H}_{2} \mathrm{O}$ 0,02\%; $\left.\mathrm{KNO}_{3} \quad 0,3 \%-\mathrm{m} / \mathrm{v}\right)$ suplementado com Glicose (1\%) e extrato de Levedura (0,1\%). Os micro-organismos foram incubados por 48 horas a $30^{\circ} \mathrm{C}$. Após o período de cultivo, a concentração bacteriana foi ajustada para o grau de turbidez 0,5 na escala de McFarland. Aproximadamente $\mathrm{um} \mathrm{mL}$ do crescimento bacteriano ajustado foi transferido para um tubo tipo Eppendorf e centrifugado a $10000 \mathrm{rpm}$ por 10 minutos. 0 sobrenadante foi descartado e as células ressuspensas em um $\mathrm{mL}$ de solução salina $(0,85 \%)$. Os tubos foram novamente centrifugados, o sobrenadante descartado e as bactérias ressuspensas em meio mínimo sem suplementação.

Foram transferidos para os poços de uma microplaca estéril: $206 \mu \mathrm{L}$ de Meio mínimo (sem suplementação), $20 \mu \mathrm{L}$ de suspensão microbiana, $20 \mu \mathrm{L}$ de solução de DCPIP (sal de sódio de 2,6-dicloroindofenol) e $4 \mu \mathrm{L}$ do hidrocarboneto utilizado como fonte de carbono. Foram testadas as seguintes substâncias: Gasolina, Querosene, Diesel e Óleos lubrificantes de diferentes viscosidades (5W-30, 10W-40, 15W-40, 20W-50, 25W-60).

Como controle positivo foi utilizado meio mínimo suplementado com Glicose (1\%), com adição apenas da suspensão microbiana e da solução de DCPIP. Como controle negativo, foi utilizado o meio mínimo sem suplementação, com adição da solução de DCPIP e do hidrocarboneto empregado como fonte de carbono, sem o inoculo bacteriano. As placas foram mantidas em estufa $\left(30^{\circ} \mathrm{C}\right)$, por 48 horas. Os resultados positivos foram determinados pela alteração de coloração do meio, inicialmente azul, para coloração branca em caso de degradação total da fonte de carbono ou azul clara no caso da degradação parcial. Os procedimentos foram realizados conforme metodologia adaptada de DE OLIVEIRA et al., (2012). Os ensaios foram realizados em triplicata.

Para os isolados que apresentaram positividade nos testes, foi realizada a caracterização morfotintorial pela coloração de Gram e Teste de Ryu. Para caracterização bioquímica foram utilizados os testes: produção de Indol, vermelho de Metila, teste da catalase, Voges-Proskauer, teste do citrato, redução de nitrato, gelatinase e fermentação de diferentes fontes de Carbono (Glicose, Lactose, frutose e sacarose).

\section{Avaliação de tolerância ao fenol}

Para teste de tolerância ao fenol, os micro-organismos foram inoculados em meio Mínimo suplementado com glicose (1\%) e mantidos sob incubação por 48 horas a $30^{\circ} \mathrm{C}$. O caldo cultivado foi centrifugado a 10000 rpm por 10 minutos, 0 sobrenadante foi descartado e as células bacterianas foram ressuspensas em solução salina $(0,85 \%)$. A suspensão bacteriana foi inoculada com auxílio de um inoculador multi-alça em meio mínimo mineral de Büshnell-Haas sólido, acrescido de Fenol em concentrações de 50, 100 e $150 \mathrm{mg} / \mathrm{L}$. As placas foram mantidas em estufa a $30^{\circ} \mathrm{C}$, e o crescimento microbiano foi avaliado com $48-72$ horas de cultivo. 


\section{RESULTADOS E DISCUSSÃO}

Dentre os isolados bacterianos testados, $23,8 \%$ apresentaram positividade nos testes de triagem para degradação de hidrocarbonetos (quadro 1). $\mathrm{O}$ isolado 7F exibiu capacidade de degradação total dos combustíveis testados (óleo diesel, gasolina e querosene), enquanto o isolado $9 \mathrm{~F}$ degradou parcialmente estas mesmas fontes de carbono testadas. A degradação de querosene foi parcial para os isolados $6 \mathrm{~F} \mathrm{e} 10 \mathrm{~F}$.

A degradação de todos os óleos lubrificantes testados foi observada parcialmente pelo isolado $7 F$, sendo a degradação dos óleos $5 \mathrm{~W} 50$ e $15 \mathrm{~W} 40$ parcial para $\mathrm{o}$ isolado $8 \mathrm{~F}$. Portanto, o isolado $7 \mathrm{~F}$ foi o micro-organismo que apresentou a capacidade mais ampla de degradação de hidrocarbonetos.

$O$ estudo de micro-organismos endofíticos com fins de fitorremediação de ambientes contaminados tem se mostrado uma área promissora. As pesquisas concentram-se nas mais diversas vertentes e vão desde a verificação da capacidade de degradação desses compostos como o proposto por RIBEIRO et al., (2011), até a inoculação desses organismos em vegetais e a verificação do potencial da combinação entre vegetal e bactéria (ANDREOLLI et al., 2013).

O presente estudo encontrou resultados semelhantes ao DE OLIVEIRA et al., (2012), quanto a degradação de diesel e gasolina utilizando a técnica do DCPIP, entretanto, encontrou um maior número de micro-organismos degradadores dos óleos lubrificantes. O uso do DCPIP promove a incorporação de elétrons durante o metabolismo bacteriano de hidrocarbonetos e tem se mostrado uma alternativa viável a prospecção de endofíticos com capacidade de degradação dessas substâncias e derivados (IONESCU et al., 2015).

QUADRO 1 - Triagem da degradação de hidrocarbonetos por isolados endofíticos de bambu

\begin{tabular}{|c|c|c|c|c|c|c|c|c|c|c|}
\hline$\stackrel{0}{\Sigma}$ & $\stackrel{\mp}{0}$ & ט & 0 & o & 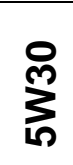 & 웅 & 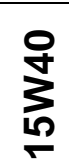 & 웅 & $\sum_{\substack{\infty \\
N}}^{\circ}$ & J \\
\hline $6 \mathrm{~F}$ & + & + & * & + & - & - & - & - & - & - \\
\hline $7 F$ & + & + & + & + & * & * & * & * & * & - \\
\hline $8 \mathrm{~F}$ & + & - & - & - & * & - & * & - & - & - \\
\hline $9 \mathrm{~F}$ & + & * & * & * & - & - & - & - & - & - \\
\hline $10 \mathrm{~F}$ & + & * & * & - & - & - & - & - & - & - \\
\hline
\end{tabular}

$\mathrm{MO}=$ micro-organismo; $\mathrm{C}(+)=$ controle positivo; 10W40, 15W40, 20W50, 25W60 e $5 \mathrm{~W} 30$ = óleo lubrificante; $\mathrm{C}(-)=$ controle negativo; $\mathrm{OD}=$ óleo diesel; $\mathrm{G}=$ gasolina; $\mathrm{Q}$ = querosene ; + = degradação positiva; - = ausência de degradação; * degradação parcial .

Os micro-organismos endofíticos estão associados a adaptação de diversas espécies vegetais a ambientes impactados com poluentes (KHAN et al., 2014). Esses organismos apresentam uma grande diversidade metabólica, sendo capazes de degradar ou agregar diversos xenobióticos, tais como pesticidas, herbicidas, 
inseticidas, derivados do petróleo e substâncias derivadas do fenol (KIM et al., 2012; STĘPNIEWSKA \& KUŹNIAR, 2013).

Embora a maioria das bactérias degradadores de hidrocarbonetos tenha sido isolada do solo, sabe-se que durante a interação com o vegetal, os endofíticos produzem uma serie de enzimas hidrolíticas envolvida na decomposição de compostos produzidos pela planta. Diversos desses compostos orgânicos, ricos em carbono e hidrogênio, apresentam uma estrutura semelhante aos hidrocarbonetos derivados do petróleo. Em algumas espécies de micro-organismos observou-se a presença de genes degradadores de hidrocarbonetos (JOUTEY et al., 2013; KUKLA et al., 2014).

O uso de bambu é comum na biorremediação de diversos poluentes, especialmente os associados a poluição aquática. Por apresentar crescimento rápido e capacidade de adaptação a diversos ambientes, o bambu tem sido considerado como uma alternativa barata e eficiente para a fitorremediação (CAO et al., 2012; CHEN et al., 2015). Pouco se conhece sobre o real potencial dos endofíticos nesse processo, sendo os estudos, em sua maioria, restrito ao estudo da capacidade de fungos isolados de bambu em degradar contaminantes (SILVA \& RONDON, 2013).

Em relação a capacidade de tolerância ao fenol, $71,42 \%$ dos isolados apresentaram crescimento em todas a concentrações testadas. Dentre os microorganismos que apresentaram capacidade de degradação total ou parcial de hidrocarbonetos, apenas 0 isolado 9F foi incapaz de crescer nas diferentes concentrações de fenol testadas. A caracterização dos isolados que apresentaram positividade nos testes de triagem para degradação de hidrocarbonetos é apresentada no quadro 2.

Valores inferiores quanto a tolerância ao fenol foram encontrados por GAYATHRL et al., (2010), em que 55,5\% dos isolados endofíticos demonstraram a capacidade de crescer em meio de cultura suplementado com fenol. A capacidade de tolerar o fenol não está associada necessariamente a capacidade de degradá-lo, pois foi observado em alguns grupos bacterianos um sistema de efluxo de compostos aromáticos. (WANG et al., 2007). Os compostos fenólicos são responsáveis pela diminuição da carga microbiana global do vegetal, portanto, bactérias que toleram o fenol são extremamente importantes por continuarem viáveis e produzindo outras substâncias que caracterizam a simbiose com o vegetal, tais como os fatores de promoção de crescimento vegetal (SOLEIMANI et al., 2010).

O que se observa é uma tendência por parte dos pesquisadores em isolar micro-organismos degradadores de fenol a partir de ambientes previamente impactados, utilizando meios seletivos suplementados com fenol (MOHITE et al., 2010; BUL et al., 2012; KAFILZADEH et al., 2013). Essa prática subestima os bons resultados que os endofíticos possam apresentar. Embora a maior parte da contaminação por fenol seja pelo impacto da ação do homem, os compostos fenólicos são naturalmente produzidos como produtos de degradação de polímeros que contenham anéis aromáticos, tais como a lignina e a tanina ou ainda como componente do exsudato produzido pelas raízes (VAN SCHIE \& YOUNG, 1998). 
QUADRO 2 - Caracterização dos isolados endofíticos de bambu

\begin{tabular}{cccccc}
\hline & $6 \mathrm{~F}$ & $7 \mathrm{~F}$ & $8 \mathrm{~F}$ & $9 \mathrm{~F}$ & $10 \mathrm{~F}$ \\
\hline Morfologia & Bacilo & Bacilo & Bacilo & Bacilo & Bacilo \\
Gram & + & - & + & + & + \\
Ryu & - & + & - & - & - \\
Endósporo & - & - & - & - & - \\
Teste do citrato & + & - & - & - & - \\
Catalase & + & + & + & + & + \\
Redução de Nitrato & - & + & - & - & - \\
Produção de Indol & - & - & - & - & - \\
VP & - & - & + & - & + \\
Gelatinase & + & + & + & + & + \\
Ornitina & - & - & + & - & + \\
Vermelho de Metila & - & - & + & - & - \\
Fermentação Glicose & + & - & - & - & - \\
Fermentação Lactose & - & - & - & - & - \\
Fermentação Frutose & + & - & - & - & + \\
Fermentação Sacarose & - & - & + & - & - \\
\hline
\end{tabular}

Acredita-se que os micro-organismos associados as plantas tenham papel chave na degradação de poluentes e que a fitorremediação desses compostos não seria possível somente pelo vegetal (BISHT et al., 2015). Ambientes contaminados com fenol estão relacionados a uma maior expressão de genes da classe das monooxigenases, que desempenham papel importante na hidrolização catalítica de compostos aromáticos. Esses genes estão presentes nos micro-organismos rizosfericos e endofíticos e há evidências de transferência horizontal de genes de degradação entre esses grupos (WANG et al., 2007; PENG et al., 2015). Devido a versatilidade metabólica, os endofíticos podem ser uma boa alternativa para busca de biorremediadores, possuindo simultaneamente a capacidade de degradar tanto 0 fenol como os hidrocarbonetos, como no caso dos isolados 6F, 7F, 8F e 10F.

\section{CONCLUSÃO}

A utilização de plantas na remediação de ambientes contaminados por poluentes orgânicos pode ser aprimorada pelo uso concomitante de microorganismos endofíticos. Nesse sentido, os resultados demonstram uma grande potencialidade de alguns isolados bacterianos obtidos, abrindo possibilidades para avaliação da aplicabilidade destas bactérias em um sistema de fitorremedição, na recuperação de áreas afetadas pela exposição a hidrocarbonetos e fenol. $\mathrm{O}$ estudo dos micro-organismos endofíticos associados a espécies de bambu pode ser 
biotecnologicamente bastante estratégico. A exploração das propriedades de interesse de bactérias endofíticas expõe a importância que a prospecção destes micro-organismos pode exercer sobre o surgimento de ferramentas que atendam a demanda crescente por novas tecnologias destinadas a remediação de ambientes impactados pela atividade antropogênica.

\section{REFERÊNCIAS}

AFZAL, M.; KHAN, Q. M.; SESSITSCH, A. Endophytic bacteria: prospects and applications for the phytoremediation of organic pollutants. Chemosphere, v. 117, p. 232-242, $2014 . \quad$ Disponível em: <http://dx.doi.org/10.1016/j.chemosphere.2014.06.078>. 10.1016/j.chemosphere.2014.06.078

ANDREOLLI, M.; LAMPIS, S.; POLI, M.; GULLNER, G.; BIRO, B.; VALLINI, G. Endophytic Burkholderia fungorum DBT1 can improve phytoremediation efficiency of polycyclic aromatic hydrocarbons. Chemosphere, v. 92, n. 6, p. 688-694, 2013. Disponível em: <http://dx.doi.org/10.1016/j.chemosphere.2013.04.033>. doi: 10.1016/j.chemosphere.2013.04.033

BISHT, S.; PANDEY, P.; BHARGAVA, B.; SHARMA, S.; KUMAR, V.; SHARMA, K. Bioremediation of polyaromatic hydrocarbons (PAHs) using rhizosphere technology. Brazilian Journal of Microbiology, v. 46, n. 1, p. 7-21, 2015. Disponível em: <http://dx.doi.org/10.1590/S1517-838246120131354>. doi: 10.1590/S1517838246120131354

BUL, H. B.; NGUYEN, L. T.; LONG DUC, D. Biodegradation of phenol by native bacteria isolated from dioxin contaminated soils. Journal of Bioremediation and Biodegradation, v.3, n. 11, p. 1-6, 2012. Disponível em: <http://dx.doi.org/:10.4172/2155-6199.1000168>. doi: 10.4172/2155-6199.1000168

CAO, W.; ZHANGB, H.; WANGA, Y.; PANC, J. Bioremediation of polluted surface water by using biofilms on filamentous bamboo. Ecological Engineering, v. 42, p. 146-149, 2012. Disponível em: <http://dx.doi.org/:10.1016/j.ecoleng.2012.02.018>. doi: 10.5902/223611707757:10.1016/j.ecoleng.2012.02.018

CHEN, J. R.; PENG, D.L.; SHAFI, M.; LI, S.; WU, J. S.. YE, Z. Q.; WANG, Y.; YAN, W. B.; LIU, D. Phytoremediation potential of moso bamboo (Phyllostachys pubescens) for zinc and ultrastructure changes under zinc toxicity. Russian Journal of Ecology, v. 46, n. 5, p. 444-449, 2015. Disponível em: <http://dx.doi.org/10.1134/S1067413615050070>. doi: 10.1134/S1067413615050070

D'ANDREA, M. A.; REDDY, K. Crude oil spill exposure and health effects. Journal of Occupational and Environmental Medicine, v. 56, n. 10, p. 1029-1041, 2014. Disponível em: <http://dx.doi.org/10.1097/JOM.0000000000000217>. doi: 10.1097/JOM.0000000000000217

DAS, N.; CHADRAN, P. Microbial degradation of petroleum hydrocarbon contaminants: an overview. Biotechnology Research International, v. 2011, p. 1- 
13, 2011. Disponível em: <http://dx.doi.org/10.4061/2011/941810>. doi: $10.4061 / 2011 / 941810$

DE OLIVEIRA, N. C.; RODRIGUES, A. A.; ALVES, M. I. R.; ANTONIOSI FILHO, N. R.; SADOYAMA, G.; VIEIRA, J. D. G. Endophytic bacteria with potential for bioremediation of petroleum hydrocarbons and derivatives. African Journal of Biotechnology, v. 11, n. 12, p. 2977-2984, 2012. Disponível em: <http://dx.doi.org/10.5897/AJB10.2623>. doi: 10.5897/AJB10.2623

DOTY, S. L. Enhancing phytoremediation through the use of transgenics and endophytes. New Phytologist, v. 179, n. 2, p. 318-333, 2008. Disponível em: <http://dx.doi.org/10.1111/j.1469-8137.2008.02446.x>. doi: 10.1111/j.14698137.2008.02446.x

DUDEJA, S. S.; GIRI, R.; SAINI, R.; SUNEJA-MADAN, P.; KOTHE, E. Interaction of endophytic microbes with legumes. Journal of Basic Microbiology, v. 52, n. 3, p. 248-260, 2012. Disponível em: <http://dx.doi.org/10.1002/jobm.201100063>. doi: $10.1002 / j o b m .201100063$

FUENTES, S.; MÉNDEZ, V.; AGUILA, P.; SEEGER, M. Bioremediation of petroleum hydrocarbons: catabolic genes, microbial communities, and applications. Applied Microbiology and Biotechnology, v. 98, n. 11, p. 4781-4794, 2014. Disponível em: <http://dx.doi.org/10.1007/s00253-014-5684-9>. doi: 10.1007/s00253-014-5684-9

GAYATHRI, S.; SARAVANAN, D.; RADHAKRISHNAN, M.; BALAGURUNATHAN,R.; KATHIRESAN, K. Bioprospecting potential of fast growing endophytic bacteria from leaves of mangrove and salt-marsh plant species. Indian Journal of Biotechnology, v. 9, n. 4, p. 397-402, 2010.

GERHARDT, K. E.; HUANG, X. D.; GLICK, B. R.; GREENBERG, B. M. Phytoremediation and rhizoremediation of organic soil contaminants: potential and challenges. Plant Science, v. 176, n. 1, p. 20-30, 2009. Disponível em: $<$ http://dx.doi.org/10.1016/j.plantsci.2008.09.014>. 10.1016/j.plantsci.2008.09.014

IJAZ, A.; IMRAN, A.; HAQ, A.; KHAN, Q. M.; AFZAL, M. Phytoremediation: recent advances in plant-endophytic synergistic interactions. Plant and Soil, p. 1-17, 2015. Disponível em: <http://dx.doi.org/10.1007/s11104-015-2606-2>. doi: 10.1007/s11104-015-2606-2

IONESCU, R.; MARUTESCUB, L.; TANASEA, A. M.; CHICIUDEANA, I.; CSUTAKA, O.; PELINESCUA, D.; VASSUA, T.; STOICAA, I. Flow Cytometry Based Method for Evaluation of Biodegradative Potential of Pseudomonas fluorescens. Agriculture and Agricultural Science Procedia, v. 6, p. 567-578, 2015. Disponível em: $<$ http://dx.doi.org/:10.1016/j.aaspro.2015.08.088>. 10.1016/j.aaspro.2015.08.088

ITE, A. E.; IBOK, U. J.; ITE, M. U.; PETTERS, S. W. Petroleum exploration and production: past and present environmental issues in the Nigeria's Niger Delta. 
American Journal of Environmental Protection, v. 1, n. 4, p. 78-90, 2013. Disponível em: <http://dx.doi.org/10.12691/env-1-4-2>. doi: 10.12691/env-1-4-2

JOUTEY, N. T.; BARAFID, W.; SAYEL, H.; EL GHACHTOULI, N.. Biodegradation: involved microorganisms and genetically engineered microorganisms. Biodegradation-life of science. InTech, Rijeka, p. 289-320, 2013. Disponível em: <http://http://dx.doi.org/10.5772/56194>. doi: 10.5772/56194

KAFILZADEH, F.; FARHANGDOOST, M.; TAHERY, Y. Isolation and identification of phenol degrading bacteria from Lake Parishan and their growth kinetic assay. African Journal of Biotechnology, v. 9, n. 40, p. 6721-6726, 2013. Disponível em: <http://dx.doi.org/:10.5897/AJB10.665>. doi: 10.5897/AJB10.665

KHAN, S.; AFZAL, M.; IQBAL, S.; KHAN, Q. M. Plant-bacteria partnerships for the remediation of hydrocarbon contaminated soils. Chemosphere, v. 90, n. 4, p. 13171332, 2013. Disponível em: <http://dx.doi.org/10.1016/j.chemosphere.2012.09.045>. doi: 10.1016/j.chemosphere.2012.09.045

KHAN, Z.; ROMAN, D.; KINTZ, T.; ALAS, M.; YAP, R.; DOTY, S.. Degradation, phytoprotection and phytoremediation of phenanthrene by endophyte Pseudomonas putida, PD1. Environmental science \& technology, v. 48, n. 20, p. 12221-12228, 2014. Disponível em: <http://dx.doi.org/10.1021/es503880t>. doi: 10.1021/es503880t

KIM, T.; CHO, S. H.; HAN, J. H.; SHIN, Y. M.; LEE, H. B.; KIM, S. B. Diversity and physiological properties of root endophytic actinobacteria in native herbaceous plants of Korea. The Journal of Microbiology, v. 50, n. 1, p. 50-57, 2012. Disponível em: <http://dx.doi.org/10.1007/s12275-012-1417-x>. doi: doi:10.1007/s12275-012-1417-x

KUKLA, M.; PŁOCINICZAK, T.; PIOTROWSKA-SEGET, Z. Diversity of endophytic bacteria in Lolium perenne and their potential to degrade petroleum hydrocarbons and promote plant growth. Chemosphere, v. 117, p. 40-46, 2014. Disponível em: <http://dx.doi.org/10.1016/j.chemosphere.2014.05.055>. doi:

LAGHLIMI, M.; BAGHDAD, B.; EL HADI, H.; BOUABDLI, A. Phytoremediation mechanisms of heavy metal contaminated soils: a review. Open Journal of Ecology, v. 5, n. 8, p. 375-388, 2015. Disponível em: <http://dx.doi.org/10.4236/oje.2015.58031>. doi: 10.4236/oje.2015.58031

LI, H. Y.; WEI, D. Q.; SHEN, M.; ZHOU, Z. P. Endophytes and their role in phytoremediation. Fungal Diversity, v. 54, n. 1, p. 11-18, 2012. Disponível em: <http://dx.doi.org/10.1007/s13225-012-0165-x>. doi: 10.1007/s13225-012-0165-x

LIU, P. G.; CHANG, T. C.; WHANG, L. M.; KHAO, C. H.; PAN, P. T.; CHENG, S. S. Bioremediation of petroleum hydrocarbon contaminated soil: effects of strategies and microbial community shift. International Biodeterioration \& Biodegradation, v. 65, n. $8, \quad$ p. 1119-1127, 2011. Disponível em: <http://dx.doi.org/10.1016/j.ibiod.2011.09.002>. doi: 10.1016/j.ibiod.2011.09.002 
MOHITE, B. V.; JALGAONWALA, R.; PAWAR, S.; MORANKAR, A. Isolation and characterization of phenol degrading bacteria from oil contaminated soil. Innovative Romanian Food Biotechnology, v. 7, p. 61-65, 2010. Disponível em: <http://www.bioaliment.ugal.ro/revista/7/paper\%2078.pdf>.

PENG, A.; LIU, J.; LING, W.; ZEYOU, C.; GAO, Y. Diversity and distribution of $16 \mathrm{~S}$ rRNA and phenol monooxygenase genes in the rhizosphere and endophytic bacteria isolated from PAH-contaminated sites. Scientific Reports, v. 5, p. 1-12, 2015. Disponível em: <http://dx.doi.org/10.1038/srep12173>. doi: 10.1038/srep12173.

PINEDO, J.; IBÁNES, R.; LIJZEN, J. P. A.; IRABIEN, Á. Assessment of soil pollution based on total petroleum hydrocarbons and individual oil substances. Journal of Environmental Management, v. 30, p. 72-79, 2013. Disponível em: <http://dx.doi.org/10.1016/j.jenvman.2013.08.048>.

doi: 10.1016/j.jenvman.2013.08.048

RAJKUMAR, M.; SANDHYA, S.; PRASAD, M. N. V.; FREITAS, H. Perspectives of plant-associated microbes in heavy metal phytoremediation. Biotechnology Advances, v. $30, \quad$ n. 6, p. 1562-1574, 2012. Disponível em: <http://dx.doi.org/10.1016/j.biotechadv.2012.04.011>. 10.1016/j.biotechadv.2012.04.011

REINHOLD-HUREK, B.; HUREK, T. Living inside plants: bacterial endophytes. Current Opinion in Plant Biology, v. 14, n. 4, p. 435-443, 2011. Disponível em: <http://dx.doi.org/10.1016/j.pbi.2011.04.004>. doi: 10.1016/j.pbi.2011.04.004

RIBEIRO, H.; MUCHA, A. P.; ALMEIDA, C. M.; BORDALO, A. A.Hydrocarbon degradation potential of salt marsh plant-microorganisms associations. Biodegradation, v. 22, n. 4, p. 729-739, 2011. <http://dx.doi.org/10.1007/s10532010-9446-9>. doi: 10.1007/s10532-010-9446-9

SILVA, M. B.; RONDON, J. N. UTILIZAÇÃO DE FUNGO DE BAMBU NA BIORREMEDIAÇÃO DE SOLO CONTAMINADO. Revista Eletrônica em Gestão, Educação e Tecnologia Ambiental, v. 10, n. 10, p. 2175-2184, 2013. Disponível em: <http://dx.doi.org/10.5902/223611707757>. doi: 10.5902/223611707757

SOLEIMANI, M.; AFYUNI, M.; HAJABBASI, M. A.; NOURBAKHSH, F.; SABZALIAN, M. R..; CHRISTENSEN, J. H. Phytoremediation of an aged petroleum contaminated soil using endophyte infected and non-infected grasses. Chemosphere, v. 81, n. 9, p. 1084-1090, 2010. Disponível em: <http://dx.doi.org/10.1016/j.chemosphere.2010.09.034>. doi: 10.1016/j.chemosphere.2010.09.034

STEPNIEWSKA, Z.; KUZNIAR, A. Endophytic microorganisms - promising applications in bioremediation of greenhouse gases. Applied Microbiology and Biotechnology, v. 97, n. 22, p. 9589-9596, 2013. Disponível em: <http://dx.doi.org/10.1007/s00253-013-5235-9>. doi: 10.1007/s00253-013-5235-9 
VAN SCHIE, P. M.; YOUNG, L. Y. Isolation and characterization of phenol-degrading denitrifying bacteria. Applied and Environmental Microbiology, v. 64, n. 7, p. 2432-2438, 1998. Disponível em: <http://dx.doi.org/0099-2240/98/\$04.0010>. doi: $0099-2240 / 98 / \$ 04.0010$

WANG, Y.; XIAO, M.; GENG, X.; LIU, J.; CHEN, J. Horizontal transfer of genetic determinants for degradation of phenol between the bacteria living in plant and its rhizosphere. Applied Microbiology and Biotechnology, v. 77, n. 3, p. 733-739, 2007. Disponível em: <http://dx.doi.org/10.1007/s00253-007-1187-2>. doi: $10.1007 / \mathrm{s} 00253-007-1187-2$

WEYNES, N.; CROES, S.; DUPAE, J.; NEWMAN, L.; van der LELIE, D.; CARLEER, R.; VANGRONSVELD, J. Endophytic bacteria improve phytoremediation of $\mathrm{Ni}$ and TCE co-contamination. Environmental Pollution, v. 158, n. 7, p. 2422-2427, 2010. Disponível em: <http://dx.doi.org/10.1016/j.envpol.2010.04.004>. doi: 10.1016/j.envpol.2010.04.004 